\title{
O ÍNDIO, O BRANCO E O NEGRO EM MARTIUS, VARNHAGEN E CAPISTRANO
}

The indian, the white and the black man in Martius, Varnhagen and Capistrano

Ábdon Eres da Silva ${ }^{1}$

RESUMO: Em 1844 o IHGB lançou um concurso para escolher um projeto para escrever a história do Brasil. Martius foi o vencedor, com um trabalho que focava na convergência de três raças para a formação do país: o negro, o branco e o índio. Nenhum historiador conseguiu levar à frente uma história na íntegra aos moldes de Martius. Porém, tempos depois, dois historiadores brasileiros escreveram sua visão sobre a história do Brasil: Capistrano de Abreu e Adolfo de Varnhagen. Levando em conta a relevância de Martius na historiografia ainda hoje pelas suas propostas para a história do país, até que ponto os escritos de Capistrano e Varnhagen, dois renomados historiadores do Brasil, teriam atendidos aos anseios de Martius, conscientemente ou não, sobre os três povos que formaram a população brasileira?

PALAVRAS-CHAVE: Martius; Varnhagen; Capistrano; História do Brasil.

ABSTRACT: In 1844 the IHGB launched a competition to choose a project to write the history of Brazil. Martius was the winner, with a work that focused on the convergence of three races for the country's formation: the black, white and Indian. No historian could carry forward a story to the full Martius molds. However, sometime later, two Brazilian historians wrote his vision of the history of Brazil: Capistrano de Abreu and Adolfo de Varnhagen. Taking into account the relevance of Martius in historiography today's proposals for the country's history, to what extent the writings of Capistrano and Varnhagen, two renowned historians of Brazil, would have met the wishes of Martius, consciously or not, on the three people who formed the Brazilian population?.

KEYWORDS: Martius; Varnhagen; Capistrano; History of Brazil.

\section{Introdução}

Em 1838 foi criado no Rio de Janeiro o Instituto Histórico e Geográfico Brasileiro (IHGB) com o objetivo de reunir e organizar materiais (documentos e fontes) para escrever a história do Brasil. Assim, o IHGB, organizou missões para fora do país com o intuito de coletar

\footnotetext{
${ }^{1}$ Graduado em Licenciatura em História pela Universidade Federal do Piauí - UFPI.
} 
documentos que viessem a ser úteis para a história do país. Procurou também manter contato com instituições semelhantes em outras partes do mundo e preocupou-se em publicar escritos sobre o Brasil colonial e divulgar fontes sobre a América portuguesa.

Em um contexto em que era preciso produzir uma história do Brasil que desse um perfil à sociedade brasileira e que abarcasse a diversidade do país, o recém criado IHGB se mostrou aberto para receber ideias de como esta história poderia ser escrita. Assim, foi aberto um concurso em 1844 para escolher o trabalho que melhor definisse a maneira de se escrever a história brasileira. O vencedor do prêmio foi o naturalista Karl Von Martius, que escreveu "Como se deve escrever a história do Brasil".

A intenção do IHGB era que as ideias contidas no modelo de história vencedor do concurso fossem colocadas em prática por seus historiadores. Mas, provavelmente, pelo fato de o modelo de Martius ser muito abrangente, nenhum historiador foi capaz de escrever uma história tal como ele propôs, não em sua integridade.

Mesmo assim, na historiografia brasileira tivemos diversos autores que escreveram aos brasileiros a sua interpretação da história do Brasil. Dentre eles, dois se destacam pela contribuição que suas obras deixaram para esta área. Varnhagen e Capistrano. Dois historiadores reconhecidos.

Varnhagen e Capistrano não foram contemporâneos, mas viveram em épocas não muito distantes no tempo. Varnhagen escreveu uma história brasileira centrada no olhar português, exaltando os valores da monarquia e Capistrano escreveu na perspectiva dos nativos, tratando o português como um alienígena ao continente.

De acordo com José Carlos Reis ${ }^{2}$, Varnhagen tomou para si a tarefa de escrever a história do Brasil tal como Martius propôs. E Capistrano focou-se em consertar as lacunas que Varnhagen deixou em sua obra, autor que admirava e ao mesmo tempo era rival.

Tendo como base o que Martius escreveu sobre a importância da convergência das três raças (branco, negro e índio) para a formação do povo brasileiro, como Varnhagen e Capistrano trataram da participação delas nas suas respectivas escrita da História do Brasil?

Mesmo se tratando de obras posteriores e considerando que os seus autores podem ou não ter tido a intenção de seguir o modelo proposto por Martius para escreverem suas obras, pelo fato de "Como escrever a história do Brasil" ter sido aceita como a melhor maneira de se produzir algo sobre o Brasil, pelos elementos que abrangem e que foram, por consenso, aceitas

2 REIS, José Carlos. As identidades do Brasil: de Varnhagen a FHC. 8 ed. Rio de Janeiro: Editora FGV, 2006. p. 28. 
pelo tão renomado IHGB, torna-se importantíssimo analisar alguns aspectos dos escritos de Varnhagen e Capistrano à luz do que foi proposto por Martius.

Martius foi inovador no seu projeto para a história do Brasil. Considerou como relevantes para a formação do país dois povos que na época eram, podemos assim dizer, desprezados pela sociedade: o índio e o negro. O índio ainda sofria com o extermínio e os negros submetidos a uma intensa jornada de trabalho.

Portanto, o foco deste artigo é perceber até que ponto Varnhagen e Capistrano foram capazes de atender aos anseios do projeto de Martius, mesmo que inconscientemente; se for o caso, nas suas obras de interpretação do passado do Brasil, no que se refere aos três povos que Martius fez questão de destacar como essenciais para a formação do povo brasileiro.

\section{Como se deve escrever a História do Brasil - Karl Von Martius}

Karl Friedrich Philipp Von Martius nasceu em 17 de Abril de 1794 em Erlagen, na Baviera (Alemanha). Demonstrou interesse pela botânica desde cedo, provavelmente influenciado pela família que era tradicionalmente vinculada às Ciências Naturais. Em 1816 foi convocado a participar da Comissão de Naturalistas que viajaria para o Brasil para estudar a sua fauna e a sua flora.

No Brasil, Martius - junto com Johan Baptist Von Spix - também membro da comissão de naturalistas, percorreram extensas áreas do país, em torno de 1400 milhas geográficas, e incluindo aí as regiões de centro, do leste, do nordeste e Amazônia. A expedição dos dois obteve excelentes resultados, principalmente quando se observa a quantidade de espécimes coletadas: 6500 de plantas, 85 de mamíferos, 350 de aves, 130 de anfíbios, 116 de peixes e 27000 de insetos.

Martius sentiu imenso prazer quando leu que o IHGB desejava ideias para a escrita da história do Brasil. O que mostra que o naturalista tinha muito interesse neste assunto, mesmo achando-se incapaz de competir com os "ilustres literatos brasileiros habilitados para preencherem as vistas do Instituto."3

O ponto essencial para se escrever a história do Brasil é, segundo ele, a formação do homem que aconteceu por meio da mistura tanto sanguínea quanto das relações estabelecidas entre elas, de três raças distintas: a branca, a indígena e a negra. Três raças com características únicas formaram um povo novo, e é justamente essa formação que exige que a nossa história seja tratada de modo particular.

\footnotetext{
${ }^{3}$ MARTIUS, Karl Friedrich Von. Como se deve escrever a História do Brasil. In: Revista de História de América, N 42, (Dec., 1956), pp. 433-458. Publicado pela: Pan American Institute of Geography and History. Disponível em: <HTTP://www.jstor.org/stable/20137096>. Acesso em: 07/08/2013. p. 441.
} 
Cada um desses povos deu suas influências para a formação da população brasileira. Porém, a contribuição maior foi a do povo cuja "energia, número e dignidade da sociedade" superou as demais raças, no caso os portugueses. Não porque eram brancos, mas porque destacaram-se em suas investidas colonizadoras, impondo-se poderosamente sobre as outras raças. Mesmo considerando os portugueses como raça dominante, sobre a qual a indígena e a negra viria reagir, o que mais chama a atenção é o fato de Martius dar relevância a cada uma delas na formação do país, colocando-as uma ao lado da outra e não uma superior a outra.

Assim, Martius elenca cada uma das raças, dispondo-as segundo a ordem de sua penetração nas terras brasileiras: índios, portugueses e negros.

Quanto aos índios, Martius destaca, inicialmente, a necessidade de se investigar a sua história, passando por períodos que antecedem a conquista portuguesa, de modo a contribuir na elucidação de muitos elementos da vida dos aborígenas. Depois de conhecer a natureza "original" dos indígenas, o próximo passo será entender como essa natureza foi transformada pelos outros povos.

Ele acrescenta ainda que é necessário estudar os índios tendo por base as suas manifestações exteriores. Assim, ele sugere que seja estudada a língua dos índios, analisando os radicais desta fala e, inclusive, produzindo dicionários. Isso permitiria compreender mais sobre a vivência dos índios e sobre os seus costumes.

O último passo a ser realizado é observar as relações jurídicas e sociais dos índios, que vivem juntos em uma mesma tribo, seguindo comportamentos típicos da sua sociedade.

Para falar do português, Martius destaca a importância das milícias portuguesas que combatiam as invasões hostis dos indígenas, favoreciam a sua incursão pelo território e que ainda foi útil para o combate aos demais europeus que ameaçavam invadir o Brasil. Martius afirma ainda que a chegada ao Brasil não pode ser justificada pelas mesmas razões que levaram, por exemplo, os ingleses a saírem da Inglaterra. A emigração dos portugueses para o Novo Mundo não se constituiu pela movimentação apenas de pessoas pobres, perseguidas por causa da sua religião ou por outros fatores, mas "era antes uma consequência das grandes descobertas e empresas comerciais dos portugueses sobre a Costa Ocidental da África, do Cabo, Moçambique e Índia", ${ }^{5}$ isto é, foi contextualizada pela expansão marítima de Portugal.

Sendo assim, o historiógrafo do Brasil deveria estar atento às motivações do comércio universal, sendo imprescindível, neste aspecto, realizar uma história comparativa do comércio da Índia e da América. Isso se torna necessário porque Martius acredita que a história do Brasil está

${ }^{4}$ Ibidem. p. 443.

5 Ibidem, p. 449. 
estreitamente ligada à história da procura de produtos orientais e posteriormente de produtos encontrados no Brasil, como, por exemplo, o interesse pelo comércio do Pau Brasil, que foi responsável pela nomeação do país. $\mathrm{O}$ autor também considera a importância das viagens e relações comerciais dos portugueses na África para o desenvolvimento do Brasil.

O historiador que falará sobre o Brasil também deveria traçar os costumes e o comportamento dos portugueses do século XVI como uma forma de melhor conhecer o povo que veio construir a sociedade brasileira. O próximo passo do historiador seria o estudo da legislação de Portugal, já que Martius considera que uma determinada época pode ser melhor conhecida pelo conhecimento de sua legislação vigente. Esse estudo também permitiria saber como as instituições portuguesas foram transplantadas para o Brasil, por exemplo, de que maneira as artes européias influenciaram nossas artes e de que forma o serviço e estratégias militares típica dos portugueses foram aplicadas no Brasil, um país totalmente diferente da metrópole.

Outra coisa que deverá ser tratada pelo historiador são as fábulas e contos em torno das viagens do colonizador para o interior. Conhecer as histórias e os mitos das diferentes regiões do país lhe permitirá conhecer mais as particularidades dessas populações.

Ao tratar dos negros, de início, Martius já reconhece a importância dos africanos para a formação do povo brasileiro, quando diz na primeira linha que "não há dúvida que o Brasil teria tido um desenvolvimento muito diferente sem a introdução dos escravos negros". ${ }^{6}$ Então era necessário falar sobre a condição dos negros quando estavam vindo para o Brasil, os seus costumes, valores morais e traços culturais para, desta forma, verificarmos como tudo isso reagiu sobre o Brasil.

Martius também achava importante que o historiador investigasse como era a relação dos portugueses com negros no interior da África, já que os lusos chegaram ao continente africano muito antes de chegarem ao Brasil. Essa experiência anterior luso-africana no interior da África teria sido responsável por alterações na cultura e nos valores políticos de Portugal, sendo a tarefa do historiador desvelar o nível da influência dos africanos sobre os portugueses.

Era este, então, o modelo de história do Brasil que deveria ser feito. Um modelo que abarcaria todas as características do território brasileiro, com suas especificidades e variações. Um modelo que permitiria entender as raízes de formação da sociedade brasileira, já que o modelo proposto por Martius partia não apenas do Brasil pós-colonização, mas sim das terras ainda povoadas por nativos e que só se tornaria Brasil com a colonização portuguesa que abriu portas

\footnotetext{
${ }^{6}$ Ibidem, p. 453
} 
para a miscigenação, provocando no país a convergência de três elementos específicos que se misturaram e formaram um povo novo.

$\mathrm{O}$ arquétipo de Martius, que venceu o concurso proposto pelo IHGB, estabelecia as diretrizes para produzir uma história brasileira que levaria em conta as particularidades de cada uma das diferentes regiões que formam o país sem, é claro, abrir espaço para histórias separadas dessas regiões. Propunha um estudo regional das províncias do Brasil, onde fosse retirado e realçado o que havia de mais importante em cada província para a história do país. Com isso, não se correria o risco de escrever características que se repetiam entre uma e outra província, pois elas seriam agrupadas por sua semelhança.

É notável ainda em Martius sua preocupação com a escrita de uma história que chamasse a atenção dos leitores, que pudesse ser facilmente compreendida por eles. Que tenha um caráter popular e simples, no sentido de não está escrita numa linguagem difícil e nem saturada de citações improdutivas.

Martius preocupa-se com o grau de abrangência da obra que contivesse a história brasileira. Não adiantava escrever uma história que não alcançasse o público, que não tivesse leitores interessados. Essa obra não faria sentido se os moradores do lugar sobre o qual ela fala não se identificassem com o que está escrito.

Logo isso seria um dos mais fortes empecilhos para o resultado que a história do Brasil deveria cumprir: "despertar e reanimar em seus leitores brasileiros amor da pátria, coragem, constância, indústria, fidelidade, prudência, em uma palavra, todas as virtudes cívicas."’7

\section{História Geral do Brasil - Varnhagen}

Francisco Adolfo de Varnhagen nasceu em 17 de fevereiro de 1816 em Sorocaba, São Paulo. Historiador brasileiro que ingressou na Torre do Tombo por recomendação de Alexandre Herculano e do cardeal D. Francisco de São Luís. É neste local que descobre o "Roteiro do Brasil" de Gabriel Soares de Sousa. Sobre ele fez uma edição crítica, que permitiu o seu ingresso na Academia Real de Ciências de Lisboa. Aproximadamente em 1840, Varnhagen é admitido no IHGB e ingressa no programa da instituição que mandava estudiosos para fora do país para coletar documentos que viessem a ser úteis para a escrita da história do Brasil.

Sobre os indígenas Varnhagen dedicou mais espaço do que Capistrano. As suas descrições sobre a cultura, a língua, os costumes, sobre as suas moradias, alimentação, sua

\footnotetext{
${ }^{7}$ Ibidem, p.456.
} 
disposição pelo território e a relação entre as tribos foram mais cheias de detalhes. Porém, Varnhagen não mostrou afeição pelos indígenas, desprezando e falando mal de sua condição.

Considerava-os bárbaros e criticava os seus costumes primitivos, sem compreender como alguns consideravam este estágio como tendencioso à felicidade do homem. Varnhagen era diferente dos demais membros do IHGB. Nesta instituição era predominante a corrente indianista e ele, ao contrário, inclinava-se para a valorização do português.

Sobre os negros Vanhargen tem uma visão tão negativa quanto tem dos indígenas. Dedica pouco espaço para falar sobre eles e, inclusive, coloca a sua presença no Brasil como um problema. Considera a miscigenação como uma espécie de esperança para estes problemas, torcendo para que a mistura das raças faça desaparecer a influência africana.

Nas suas considerações sobre o negro, Vanhargen critica ainda os seus costumes, mas é perceptível que se mostra contra a condição sob as quais o negro veio para o Brasil: como escravo. A necessidade de serem trazidos negros para o Brasil ele coloca como sendo culpa, em grande parte, dos jesuítas que impediam os bandeirantes de escravizá-los. Estes últimos, segundo ele, fizeram menos mal ao Brasil do que os jesuítas e os traficantes de escravos.

O tema principal da obra de Vanhargen é o português. A sua colonização é tida como o foco principal. Foi ela que trouxe o desenvolvimento do Brasil e o livrou de um futuro decadente fundado no modo vida indígena. Para ele o português é o que representa o progresso.

Essa visão de Varnhagen quanto ao branco e o seu lugar essencial na formação do Brasil, superando até mesmo o índio e o negro, é um reflexo da própria época em que ele escreve. O seu modo de ver o Brasil é uma referência das ideias que prevaleciam no século XIX, especialmente entre as elites, que defendiam que o Brasil deveria ser branco e, em hipótese alguma, negro, indígena ou misturado.

Essa concepção da preferência da hegemonia branca no seio elitista da sociedade brasileira reflete também na religião. Pensar um Brasil não católico seria uma espécie de insulto à sociedade que queria se fazer europeizada. Esse pensamento culmina, então, no desprezo à religião africana e nativa e se prolonga ainda às suas manifestações culturais.

Nas palavras de José Carlos Reis,

[...] o olhar de Varnhagen sobre a história do Brasil é, portanto, o olhar do colonizador português. Ele inicia a corrente de interpretação do Brasil que articulará os sentimentos e interesses dos "descobridores do Brasil". Ele reconstrói o Brasil, sintetiza os seus diversos ritmos temporais, submetendo-os à lógica do descobridor e conquistador. O vencedor tem todos os direitos. Vencedor, o português tem todos os direitos. Vencedor, o português impôs a sua superioridade étnica, cultural e religiosa. Eis o seu silogismo (ou sofiasma?) básico! ${ }^{8}$

${ }^{8}$ REIS, José Carlos. As identidades do Brasil: de Varnhagen a FHC. 8 ed. Rio de Janeiro: Editora FGV, 2006. p.33. 


\section{Capítulos de História Colonial - Capistrano de Abreu}

João Capistrano Honório de Abreu foi um historiador brasileiro que nasceu em 1853 no Ceará. Iniciou seus estudos na pequena cidade cearense onde nasceu, Maranguape, e continuou seus estudos em Pernambuco. A sua formação foi praticamente autodidata. Aprendeu muitas línguas entre elas as línguas indígenas, o francês e o alemão.

Em 1883 ingressou no Colégio D. Pedro II, após ter concorrido à cátedra de Corografia e História do Brasil desta escola com a tese "O descobrimento do Brasil”. Em 1887 ingressou no IHGB. Capistrano dizia ter o sonho de escrever uma "nova história" do Brasil, que se diferenciasse da feita por Varnhagen. Foi esse seu anseio que o motivou a escrever a sua obra.

Como afirma Vainfas:

[...] rival de Varnhagen, Capistrano foi, porém, paradoxalmente, um seguidor do visconde de Porto Seguro em vários aspectos. A própria idéia de fazer uma "nova história" do Brasil começou a germinar em Capistrano, de fato, não em sonho, mas a propósito de uma reedição crítica de Varnhagen, isto é, o projeto de fazer alentadas introduções a cada um dos volumes da História Geral do Brasil. Assim, surgiram alguns "Capítulos", ou esboços deles, parte dos quais publicados, em versão simplificada, a partir de 1905, na revista Kosmos do Rio de Janeiro, sob o título de "História da Pátria".

Nos seus "Capítulos de História Colonial", Capistrano de Abreu, começa com um capítulo dedicado aos indígenas, cujo nome é Antecedentes Indígenas. Neste tópico, Capistrano passa a maior parte das páginas falando sobre as características geográficas do Brasil, o que revela o seu enorme interesse nas relações entre história e geografia.

Ele destaca a localização do território do país rodeado de colônias predominantemente castelhanas, mas também inglesas, colombianas, holandesas e francesas, só para citar algumas. Daí parte para a caracterização das áreas limites das terras brasileiras e acrescenta a isso a sua descrição sobre os rios, sobre a vegetação e sobre o relevo do país.

Somente nas das duas últimas páginas é que Capistrano começa a falar sobre os índios em si. Fala superficialmente sobre a alimentação dos nativos, destacando aí a caça, a pesca e a agricultura; da sua forma de produção do fogo, por atrito e da sua divisão de tarefas, as mulheres sendo responsáveis pelas tarefas dentro da aldeia, como agricultura e preparo das comidas e das bebidas e os homens, pelas atividades fora da sua habitação, no caso a pesca, a caça e as guerras.

Capistrano fala das guerras entre os indígenas e dos costumes em torno dessas disputas, que podiam acontecer por pequenas rixas e motivações muito simples, como por exemplo, por

\footnotetext{
${ }^{9}$ VAINFAS, Ronaldo. Capistrano de Abreu: Capítulos de história colonial. In: MOTA, Lourenço Dantas (org.). Introdução ao Brasil: Um banquete no trópico. 2 ed. São Paulo: Editora SENAC São Paulo, 1999. p. 176.
} 
causa de um papagaio. Nas guerras, a aldeia vitoriosa tornava as mulheres indígenas suas aliadas e os homens eram submetidos aos rituais antropofágicos.

Eram nômades e viviam em pequenas comunidades. Capistrano continua sua análise aos indígenas descrevendo crenças como a crença nos poderes místicos dos pajés. Destaca também a sua incrível habilidade de observação da natureza, e os inúmeros talentos artísticos, representados pelas artes de cerâmicas ou de materiais naturais como cuias e trançados, pelas danças e pelas músicas.

Capistrano dedica alguns parágrafos para a análise das línguas faladas pelos índios, mostrando os grupos agregados pela linguagem e as áreas que atuam e destacando a estrutura comum nas diversas línguas indígenas, algumas, inclusive, que facilitava a tradução para o europeu, assim, os nativos, de acordo com ele:

[...] falavam línguas diversas, quanto ao léxico, mas obedecendo ao mesmo tipo: o nome substantivo tinha passado e futuro como verbo; o verbo intransitivo fazia de verdadeiro substantivo; o verbo transitivo pedia dois pronomes, um agente e outro paciente: a primeira pessoa do plural apresentava às vezes uma flexão inclusiva e outra exclusiva; no falar comum a parataxe dominava. A abundância e flexibilidade dos supinos facilitaram a tradução de certas idéias européias. ${ }^{10}$

Capistrano reserva ao negro os últimos parágrafos do segundo capítulo intitulado Fatores exóticos. Aqui ele fala sobre algumas características da sociedade lusa entre os séculos XV e XVI, como, por exemplo, alguns aspectos da índole do português e a relação entre a Igreja e o Estado. Coloca o negro na mesma posição que os portugueses: dois estranhos ao continente. E o difere dos indígenas e portugueses, porque eles têm um jeito alegre que vem acrescentar o jeito calado, tristonho e desanimado dos nativos e dos lusos.

Aproveita para descrever como, por que e em que condições os negros chegaram ao Brasil, como eles eram considerados pela sociedade, a maneira como se inseriram na vida doméstica e como as suas crenças e costumes tornaram-se instituição nacional.

\section{Martius, Varnhagen e Capistrano}

A vitória da obra de Martius no IHGB torna-se clara quando percebe-se as intenções deste instituto de criar uma história do Brasil que considerasse a diversidade brasileira, centrada especialmente, nos três povos que formaram o país, mas que deixasse o português em primeiro lugar.

A obra de Martius atendeu a estes critérios. Ele coloca o português como elemento predominante. Porém, é interessante destacar que:

\footnotetext{
10 ABREU, João Capistrano de. Capítulos de História Colonial: 1500-1800. 6. ed. Rio de Janeiro, Civilização Brasileira; Brasília, INL, 1976. p.7.
} 
Martius não defende com isso a sobreposição da raça portuguesa sobre as outras, ou um "branqueamento" da raça indígena e negra, como sendo o motor desta nova nação, mas sim a mescla das três, cada uma com a sua influência, que não necessariamente ofuscava as outras raças, pois como ele afirma "tanto os indígenas, como os negros, reagiram sobre a raça predominante". 11

Então, verifica-se que Martius defende o português como elemento predominante pelo fato de ter reagido com as outras raças, indígena e negra, e, no caso desta última, bem antes de chegar ao Brasil e, pelo fato de fazer prevalecer no recém país formado suas instituições e formas de organização.

Visão, quanto ao português, um tanto diferente da de Varnhagen que o coloca como raça superior, capaz de, com o tempo, anular a influência das demais raças; e de Capistrano que coloca o português como um estrangeiro. O pensamento de ambos torna-se diferente de Martius porque, apesar de falarem dos três em suas obras e saberem que fizeram parte da formação do país, colocam um em detrimento do outro, e não lado a lado tal como propôs Martius. Essa distância é mais perceptível em Varnahgen, na sua história tipicamente portuguesa.

Quanto ao índio, viu-se que Capistrano o coloca como primeiro elemento para formação do país e os demais como coisas à parte que vieram acrescentar o que aqui já tinha. Mesmo falando dos índios de maneira semelhante a que propôs Martius - costumes, habitações, vivências, a língua - Capistrano faz de maneira muito superficial, deixando muito a desejar.

Já Varnhagen consegue descrever muito bem as características indígenas, o problema está nos julgamentos que faz a eles, colocando-os como inferiores e bárbaros. As suas descrições foram um grande passo para o que propôs Martius, porém, tiveram a sua atenção reduzida pelas considerações negativas que fez ao modo de vida indígena.

Ao tratar dos negros, espaço bastante reduzido que foi utilizado, especialmente quando se compara aos demais povos, Martius destaca a importância de entendermos quais as suas contribuições para o português, desde as suas colônias na África. Ao lado disso, sugere que sejam pesquisadas as condições em que chegaram estes negros aqui no Brasil, os seus costumes, crenças etc., e ponderar sobre todas as influências que eles tiveram no desenvolvimento dos valores morais e políticos da sociedade.

\footnotetext{
${ }^{11}$ EVERTON, Sthênio de Sousa. Renovação na Historiografia: Martius a voz que clama no deserto. In: Simpósio Nacional de História: conhecimento histórico e diálogo social, N 27, 2013, Natal - RN, Anais... Publicado pela: Associação Nacional de História (ANPUH) Disponível em:

<HTTP://www.snh2013.anpuh.org/anais/27/13646540w39_ARQUIVO_SthenioTrabalhocompleto.pdf >. Acesso em: 09 jan.2015.p. 7.
} 
Capistrano, no também pouco espaço que dedicou aos negros, fala, semelhantemente ao que Martius sugeriu, da chegada dos negros ao Brasil até a sua inserção na sociedade:

Os primeiros negros vieram da costa ocidental, e pertencem geralmente ao grupo banto; mais tarde vieram de Moçambique. Sua organização robusta, sua resistência ao trabalho indicaramnos para as rudes labutas que o indígena não tolerava. Destinados para a lavoura, penetraram na vida doméstica dos senhores pela ama de leite e pela mucama, e tornaram-se indispensáveis pela sua índole carinhosa. ${ }^{12}$

Capistrano traz também um lado positivo da influência dos negros ao falar que trouxeram uma nota alegre para complementar o jeito "pra baixo" do português e do indígena. Considera ainda que o Brasil foi o "paraíso dos mulatos", exemplificando com o caso das mulatas, que com a sua elegância, tornaram-se verdadeiras rainhas.

Quando Varnhagen começa a falar do negro percebe-se que reconhece que o negro teve influências para a formação do Brasil, algo que já era esperado, por ser algo perceptível por todos na época. Porém, o que deixa seus argumentos um tanto distante do que propôs Martius e do que Capistrano escreveu é o fato dele colocar essa influência como algo negativo e até, de certa forma, desnecessária para a formação do país.

Em "Como se deve escrever a história do Brasil" Martius afirma que sem o negro o Brasil teria apresentado um desenvolvimento muito diferente do que tem hoje. E prossegue deixando ao historiador a decisão de dizer se este desenvolvimento foi para pior ou para melhor. Pelo que foi exposto pode-se dizer que:

Varnahgen responde afirmativamente: sim, sem os negros, o Brasil teria sido muito melhor! Foi um erro a colonização africana no Brasil. Perpetuou-se no Brasil um trabalho servil que ele se abstinha de qualificar, mas que não se pode mais dispensar sem grandes males para o país. ${ }^{13}$

Ou seja, Varnhagen não via com bons olhos a presença dos negros no Brasil, para ele a sua utilização como escravos poderia ter sido evitada, escravizando-se o indígena.

\section{Considerações finais}

Olhar as obras de Martius (Como se deve escrever a história do Brasil), Varnhagen (História Geral do Brasil) e de Capistrano (Capítulos de História Colonial) não faz tanto sentido se feita isolando uma obra em detrimento da outra. Ainda mais se deseja-se notar nestes autores as suas visões sobre o Brasil a que eles se atreviam a falar.

\footnotetext{
12 ABREU, Opus citatum, p. 11.

${ }^{13}$ REIS, José Carlos. As identidades do Brasil: de Varnhagen a FHC. 8 ed. Rio de Janeiro: Editora FGV, 2006.p.43
} 
Nesta perspectiva, o destaque é tratar como esses três autores se propuseram a tratar da tríade de povos que formaram o Brasil. Tendo por base a obra de Martius, que foi considerada um modelo a ser seguido no país, pode-se verificar como Varnhagen e Capistrano consideraram o português, o negro e o índio, que por mais que tenham colocado em suas obras abordagens semelhantes ao que propôs Martius, esses dois autores foram destoantes no que concerne como essência da obra do botânico: o reconhecimento praticamente nos mesmos patamares da influência negra, indígena e portuguesa na constituição do povo brasileiro.

\section{REFERÊNCIAS BIBLIOGRÁFICAS}

ABREU, João Capistrano de. Capítulos de História Colonial: 1500-1800. 6. ed. Rio de Janeiro, Civilização Brasileira; Brasília, INL, 1976.

EVERTON, Sthênio de Sousa. Renovação na Historiografia: Martius a voz que clama no deserto. In: Simpósio Nacional de História: conhecimento histórico e diálogo social, N 27, 2013, Natal - RN, Anais... Publicado pela: Associação Nacional de História (ANPUH) Disponível em: <HTTP://www.snh2013.anpuh.org/anais/27/13646540w39_ARQUIVO_SthenioTrabalhocom pleto.pdf >. Acesso em: 09 jan.2015.

MARTIUS, Karl Friedrich Von. Como se deve escrever a História do Brasil. In: Revista de História de América, N 42, (Dec., 1956), pp. 433-458. Publicado pela: Pan American Institute of Geography and History. Disponível em: <HTTP://www.jstor.org/stable/20137096>. Acesso em: 07/08/2013.

MOTA, Lourenço Dantas (org.). Introdução ao Brasil: Um banquete no trópico. 2 ed. São Paulo: Editora SENAC São Paulo, 1999.

REIS, José Carlos. As identidades do Brasil: de Varnhagen a FHC. 8 ed. Rio de Janeiro: Editora FGV, 2006. 